\title{
CITY PROFILE: USING SMART DATA TO CREATE DIGITAL URBAN SPACES
}

\author{
Yaxue Ma ${ }^{1}$, Gang $\mathrm{Li}^{1}$, Hui Xie ${ }^{1, *}$, Hudan Zhang ${ }^{1}$ \\ ${ }^{1}$ Center for the Studies of Information Resources, Wuhan University, Luojiashan Road 299, Wuhan, Hubei 430072, China- \\ myx_vicky@163.com, ligang@whu.edu.cn,xiehuiwhu@163.com,imiswhu@aliyun.com
}

KEY WORDS: City profile, Digital urban space, Smart city, Smart data, Urban facets

\begin{abstract}
:
In the process of modern urban development, cities face various challenges such as climate change, air pollution and poverty, which have negative effects on urban sustainable development and self-regulation. The construction of smart cities can effectively improve the capability of urban management and operation. In this paper, we aim to explore how to use the big data in urban physical, social and cyber spaces to construct smart cities. The concept of digital urban space is proposed to help achieve the construction of smart cities, and city profiling is accordingly presented as a construction method of digital urban spaces and city profile as a product. According to the goals of constructing digital urban spaces, we illustrate the conception and core implementation steps of city profiling, including urban facets modelling and urban facets profiling with smart data. With three application scenarios, we discuss how city profile can be used to meet the factual needs of management, operation and decision-making. City profile can model the cities with urban data and make them become organisms managed and operated by data, so that various information services related to the city can be provided to different users.
\end{abstract}

\section{INTRODUCTION}

Cities play an important role in the global society and economy, and have huge impacts on the environment. However, the current development of cities faces a variety of challenges from environment, energy, economy, transportation, public safety, etc. When the industrialization and urbanization have been propelled in various countries, the continuous expansion of urban population exacerbates the uncoordinated relationship between urban management capabilities and urban development goals. It triggers many negative effects that impede the development of cities leading to the continued deterioration of urban diseases.

Fortunately, the concept of smart city has been continuously expanded and perfected with the joint promotion of urban informatization and the Internet of Things, which provides a feasible idea to enhance the capabilities of urban sustainable development and self-regulation. Smart cities use information technology to connect people, information and urban components (Bakıc1 et al., 2013), and integrate various technologies, systems and services into a multi-sectorial, flexible and open-access organic network, providing governments, enterprises and the public with quality and efficient information services (Albino et al., 2015).

The construction of smart cities is truly a complex systematic project that requires the integration of multi-disciplinary knowledge. Academics, paying closer attention to data science, have gradually realized that big data offers the potential for cities to obtain valuable insights from unprecedented amount of data collected from various sources (Hashem et al., 2016; Nuaimi et al., 2015; Kitchin, 2014). Plenty of theoretical and technical explorations were conducted on the theme of datacentered smart cities (Wang, 2014). These studies focus on perceiving (Ang et al., 2017), managing (Kousiouris et al., 2017), analysing (Khan et al., 2017) and using (Aguilera et al., 2016) urban big data, which provide ideas for the construction of smart cities from different perspectives. Existing in the world where people, machines and objects are highly connected, big data is generated, updated and changed at a fast speed in the space-time network, which increases the difficulty of data processing dramatically. Therefore, in order to dynamically acquire and use big data to support specific production and living activities, it is necessary to construct an intelligent system that can integrate people, machines and objects. In the context of smart city construction, it is necessary to build a comprehensive system that is able to acquire, organize, manage and analyze urban data from physical, social and cyber spaces, so as to make full use of the data to serve the need of smart city construction.

This paper, inspired by the concepts of CPSS (Cyber-PhysicalSocial System) (Wang, 2010) and Digital Twin (Boschert \& Rosen, 2016), proposes the idea of creating digital urban spaces to assist smart city construction. It aims to explore how to use the big data in urban physical, social and cyber spaces to help construct smart cities according to the interaction among urban space. To achieve this goal, the paper further proposes the conception of city profile, which can be understood from two perspectives. Firstly, city profiling is a construction method. It builds a digital urban spatial framework that is able to cover all aspects of urban operation by modelling urban facets. And then it uses smart data derived from urban big data to characterize urban facets and their relationships, which can present the status of urban operation in a panoramic view realizing the construction of digital urban spaces. Secondly, city profile is a product of digital urban spaces that can provide a variety of information services for different users. Using data as a bridge to urban space, digital urban spaces constructed by city profiling promote the interaction and intercommunication of urban physical, social and cyber spaces, making urban space become an organism that can be managed and operated by data.

The remainder of the paper will introduce the background, conception, core implementation steps and application scenarios

* Corresponding author 
of city profile and is organized as follows. Section 2 analyses the composition of urban space and proposes the concept of digital urban space. Section 3 illustrates city profile's conception. Section 4 proposes the core implementation steps of city profiling that are used to construct digital urban spaces. Section 5 discusses three application scenarios of city profile. Section 6 summarizes the paper and presents some areas of future work.

\section{DECONSTRUCTION AND DIGITAL INTEGRATION OF URBAN SPACE}

\subsection{The Composition of urban space}

With the rapid development of computing, communication, and sensing technologies, the interconnection of all things in the cyber and physical spaces has changed the way people interact with the physical space, making the coexistence and integration of physical, social and cyber spaces more obvious (Xu et al., 2006). Considering the emergence of this transformation, it is necessary to explore and analyse specific urban issues from the perspective of three-spaces for overall control of related problems. Therefore, before exploring how to apply urban big data to build digital urban spaces, the composition and interaction of urban space should be clarified by deconstructing urban space into physical, social, and cyber spaces.

- Urban physical space refers to the one that is emphasized by architecture and urban planning, which is the external manifestation of urban space. It consists of buildings, roads, natural landscapes and other entities, and carries the main functions of city formation and evolution. Entities in physical space have spatial attributes such as volume, weight and spatial location (Zhang, 2006). People can interact with these entities by a series of behaviours like touching and manipulating. In addition, these entities are also able to be sensed and controlled by using information technologies like sensors and the Internet of Things.

- Urban social space is composed of government, various social organizations and residents, which is the source of urban vitality. As residents change and shape urban space, they are also influenced by the space. It means that urban social space is the dialectical unity of society and space (Soja, 2015). The social relations implied in this space have an important influence on the operation of cities. And with the measurability of the interaction of people-people and people-object, the potential relationship between urban social space and physical, cyber spaces can be revealed by multiple networks.

- Urban cyber space, limited by the physical space, is a virtual space that uses information flow as a tool for achieving vertical and horizontal interconnection of urban information $(\mathrm{Xu} \&$ Chen, 2013). Entities, also called objects, have no physical properties in the cyber space and are able to easily associate with each other. They are made up of data that mainly come from physical and social spaces. Being organized and integrated, these data can produce information with real value, which is able to provide significant information services for physical and social spaces in reverse.

According to the above analysis, it is not difficult to find that urban data plays an important role in the interaction of the three types of urban space. With the gradual progress of information technologies, urban physical, social and cyber spaces generate a large amount of data at all times. And data from one particular space has a certain effect on the operation of the other two. It means that data can be used as a bridge of spatial interaction. And the effective integration and connection of them in the three spaces become the basis of smart city construction as well as the premise of smart city services. It is a viable method to make use of urban data to achieve the integration of urban physical, social and cyber spaces.

\subsection{The Concept of digital urban space}

Considering the role of data in urban spatial fusion, this paper proposes the concept of constructing a digital urban space to assist the construction of smart cities based on the conceptions and technologies of CPSS, Digital Twin and data science. Digital urban spaces, attached to the cyber space, are highly intelligent spaces. On the basis of interactive relationships, the physical, social and cyber spaces are fused with the help of urban data so that problems of real-world urban operation and management can be reconstructed and solved through data processing in digital spaces.

Digital urban space uses urban big data as a bridge to create a recycling operation mechanism of urban space where urban physical, social, and cyber spaces positively support the operation of a digital urban space, and the digital urban space assists the management of three types of urban space in reverse (Figure 1). Data, sensed and acquired from urban CyberPhysical-Social spaces, is mapped into the digital urban space where it is transformed into smart data to meet the needs of urban management and operation. Digital urban spaces have the following features:

-To automate the process of data acquisition, storage, organization and analysis with the help of the Internet of Things, cloud computing and other technologies;

-To show the city's real-time performance from different perspectives;

-To dynamically select and integrate smart data for providing intelligent urban information services.

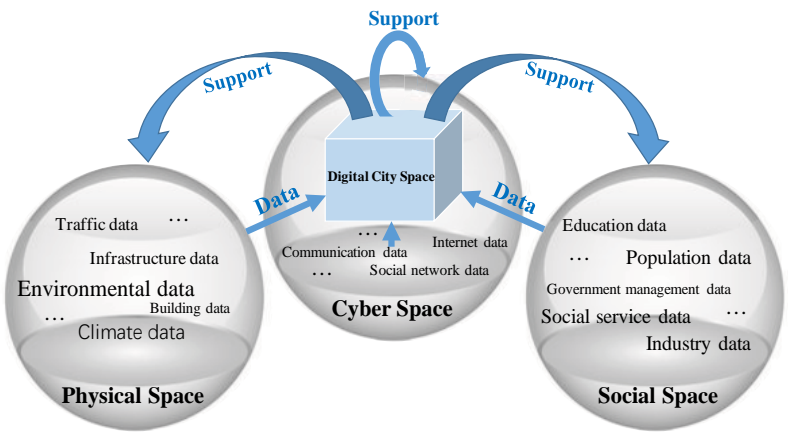

Figure 1. Operation mechanism of digital urban spaces

Digital urban spaces can comprehensively integrate data resources of urban physical, social and cyber spaces to form an urban data service system covering the entire process of data collection, organization, analysis and management. According to the logic of urban operation, it is based on the interaction of three types of urban space to guide data integration, so that the urban operational status can be presented at the data level, which can further activate the value of urban data and realize the empowerment for the construction of smart cities.

\section{THE CONCEPTION OF CITY PROFILE}

The goal of constructing smart cities that are instrumented, interconnected and intelligent can be achieved through the construction of digital urban spaces. However, building such a 
digital urban space with features of self-running and interactive is a complex systematic project, which involves a large number of technologies and theories and requires scientific methods to guide its implementation. In addition to the research on technologies of data perception and acquisition and artificial intelligence, it is also necessary to focus on how to use the method of data aggregation to build a bridge between data and artificial intelligence, so that ubiquitous perceived data can effectively serve urban intelligent management, decisionmaking and other needs, and then assist in the construction of smart cities. There are three critical problems needed to be solved, including how to cover all areas associated with urban operation and management, how to use urban data to profile the digital urban spaces, and how to use digital urban spaces to provide information services for different users. In order to address these three issues, this paper puts forward the concept of "city profile" referencing from the "user profile" (Shan et al., 2018), which realizes the gradual construction of digital urban spaces from local models to overall. It uses smart data to activate digital urban spaces, realizing panoramic and digital description of urban operation, and then provides users with information services for needs of smart city management, operation and development.

A simple understanding of city profile is to model and profile the city by using urban data, which is based on the relative theories and technologies of data science. The goal of city profile is to construct digital urban spaces with smart data to provide information services for different users. The conception of it can be understood from two perspectives:

(1) To use profile as a verb. City profiling refers to the method that is used to build digital urban spaces, which makes use of the smart data converted from urban big data to model urban space composed of different facets. This process makes it possible to quickly integrate and analyse urban data according to the specific service requirements and it can show the results through technologies like visualization.

(2) To use profile as a noun. At this point, city profile is an intuitive and meaningful product of digital urban spaces, a way of presenting information, which is generated by using smart data to analyse and visualize the specific service demands. They are usually presented in the form of charts, and can provide users with direct or indirect decision support.

City profiling does not simply integrate multiple visualization results, but organizes and analyzes relevant data according to the intrinsic business logic of different domains, and then presents them in a panoramic manner. On the one hand, it is based on data organization, fusion, and other technologies to transform urban data from the physical, social and cyber spaces into smart data, and resolves the target problem at the data level. On the other hand, it uses data as a bridge to connect cities to generate profiles of digital urban spaces, making the final presentation results able to synthesize multi-domain information, and then provides users with panoramic information support. As Kanter and Litow said, injecting intelligence into every subsystem of the city was not enough to create a smart city, because these systems should be integrated into an organic whole (Kanter \& Litow, 2009). City profiling unifies and analyses the data from urban physical, social and cyber spaces, and pays closer attention to the logical relationships among urban facets to achieve further correlation of data. It can display the state of the city from a global perspective and provide a comprehensive information support for urban management and operation by city profiles.

\section{THE CONSTRUCTION OF CITY PROFILE}

City profiling can be split into two core implementation steps, urban facets modelling and urban facets profiling with smart data. The former models every area of the urban operation, which builds a skeleton for the digital urban space. And the latter makes use of urban data to activate the framework of the digital urban space, enabling it to reflect the status of urban operation.

\subsection{Urban facets modelling}

The actual operation of a city is influenced by many factors. The support from multi-domain data is of great importance to the solution to all kinds of urban management and operation issues and it is beneficial for the completion of smart city construction. However, it will be a complicated and arduous task to achieve the unified organization and personalized service of urban data. According to the thought of system theory, the complex and comprehensive problem can be decomposed into interrelated sub-problems so as to be solved one by one, and the purpose of solving the original problem will be effectively realized. Using this idea for reference, the urban facets modelling disassembles urban space into multiple facets that can cover all areas of the city, each of which will characterize a specific urban function. And then it constructs the personalized index systems to feature the urban facets, according to the inherent business logic of each facet. After doing that, data organization of the whole city will be decomposed into that of each urban facet, and the difficulty of data organization will be also reduced. At this point, the specific needs of urban information services will be met through the personalized combination of urban facets' data, and city profiles can be generated.

The urban facets modelling is the prerequisite for the implementation of city profiling. And its realization mainly depends on the following two steps:

- The division of urban facets: a city is an integrated organism composed of many subsystems. The study of cities by decomposing them into different components enables a more complete understanding of the function and management mechanisms of cities. Urban facet is used to reflect the status of urban operation from different perspectives, which can be divided based on the composes of the city. According to the current studies on the dimensions and characteristics of smart cities, it is not difficult to find that the most common features of smart cities include networked infrastructure, commercialoriented urban development and innovation, and social integration of urban residents (Albino et al., 2015). These features are mainly reflected by the components of the city. At present, there are many researches on urban components. Among them, a representative study divides the components of a smart city into six categories, which are smart economy, smart people, smart governance, smart mobility, smart environment and smart living (Giffinger et al., 2010). They reflect, respectively, city-related areas, including Industry, education, edemocracy, logistics and infrastructures, efficiency and sustainability, and security and quality, which cover comprehensive areas of urban management and operation (Patrizia et al., 2012). In order to illustrate the conception and methods of how urban facets are modelled and how city profiling is conducted, this paper will use this division to visually explain urban facets modelling. 
- The construction of urban facet index systems: City consists of several facets, each of which has their own business logic, evaluation systems, and standards. These facets need to be characterized by using different index systems. As for the smart economy, it can be profiled by the overall strength of the city, industrial structure, innovation and development, and resources and environment, each of which can be also subdivided into multiple indicators. For example, comprehensive strength can be divided into GDP per capita, local per capita fiscal revenue, dependence on foreign trade, etc. (Lai, 2013). Similarly, the smart mobility can be profiled by smarter travel, traffic management ability, resource adaptability, environmental impact and security status (Li et al., 2016). Index systems of an urban facet constructed according to the urban features is able to effectively reflect the status quo of each facet, and it can also provide guidance for city profiling at the same time.

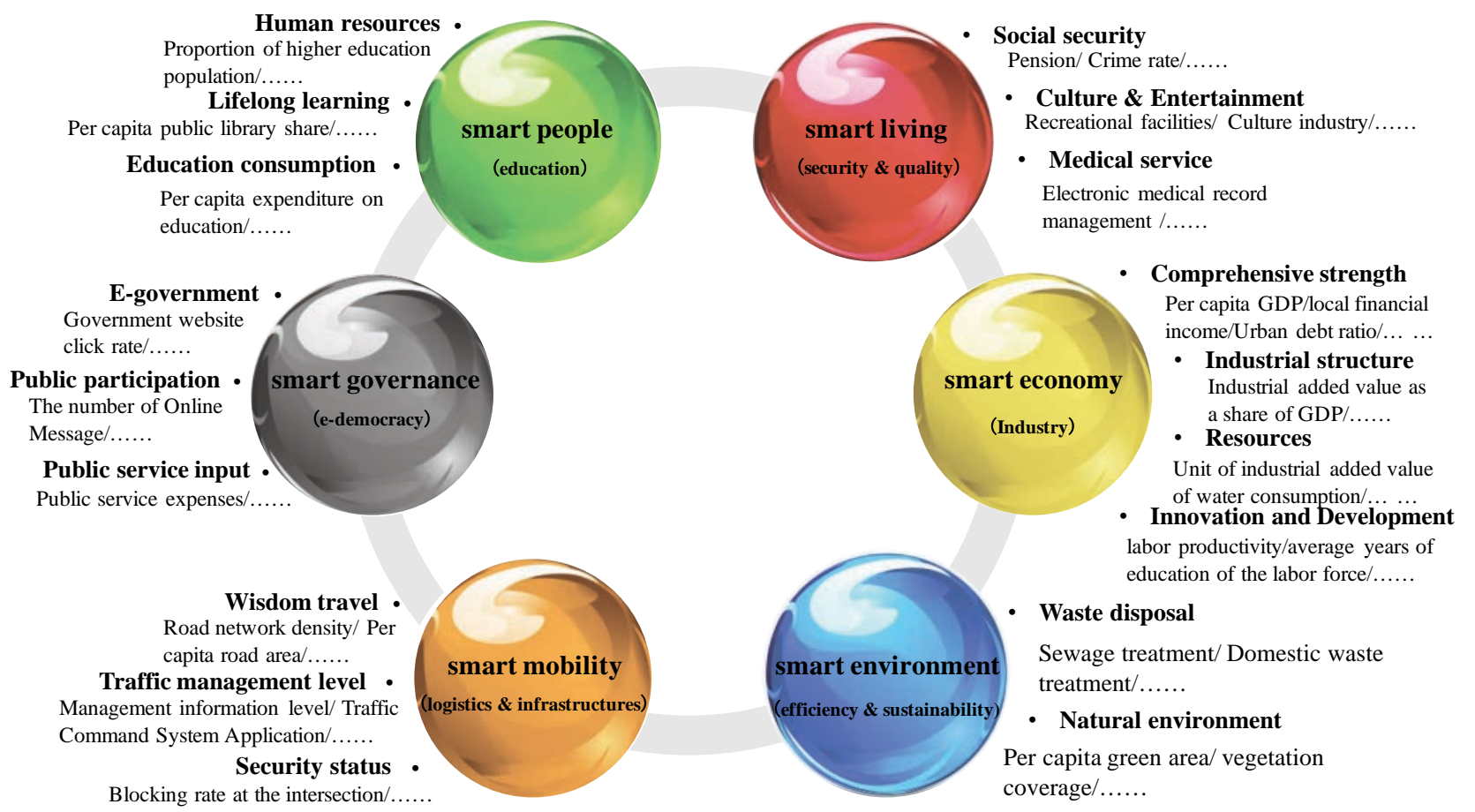

Figure 2. Facets of a digital urban space ${ }^{(1)}$

Through the division of urban facets and the construction of urban facet index systems, the faceted structure of the digital urban space is obtained, that is, the framework for the digital urban space mentioned above (Figure 2). This framework can comprehensively reflect all aspects of urban operation and management, and is the core skeleton of city profiling as well as the basis of smart city construction. It is noteworthy that the framework of a digital urban space is not static. In other words, with the continuous improvement of theory and practice related to urban management and operation, the urban components and its index systems can be dynamically optimized and adjusted so that they can more completely cover all areas of the city. At the same time, with the change of composition of urban spatial data, the framework can also be amended according to the actual acquisition of urban big data. It will realize the self-optimization of a digital urban space driven by data.

\subsection{Urban facets profiling with smart data}

Urban facets modelling provides a guidance for city profiling, but the construction of digital urban spaces requires the support of city-related data. With the progress of information technologies, the data in all areas of a city shows an explosive growth, forming the urban big data circumstance. However, if urban big data with multi- $\mathrm{V}$ features wants to provide scientific information services and to support smart city construction, it needs to be transformed into smart data to demonstrate data value.

Simply speaking, smart data makes sense out of big data (Zeng, 2017). With the characteristics of trusted, contextualized, relevant, cognitive, predictive and consumable, smart data provides value from harnessing the challenges posed by Volume, Velocity, Variety and Veracity of big data, in-turn providing actionable information and improving decision making (Sheth, 2014). City profiles drawn from it can provide valuable information to serve different users.

Cities can be profiled with smart data by the following three steps (Figure 3). Firstly, according to data requirements of each urban facet, urban big data in physical, social and cyber spaces is mapped to the digital urban space through technologies such as the Internet of Things, sensors and the Internet. In this process, data will be classified to serve the different needs of each urban facet. Secondly, data in each urban facet will be organized by using relevant technologies of data science, computer science and other disciplines, and will be converted into smart data so that it can profile each facet of the city effectively, producing city profiles of specific urban facet. For example, in the facet of smart economy, data associated with the

(1) The six dimensions in the figure are derived from "Smart cities ranking: an effective instrument for the positioning of the cities?" (Giffinger et al., 2010), and the relevant indicators are derived from "Study on the System of Evaluation for Wisdom City Construction--Nanjing as the Case" (Chen et al., 2011), "Research on the Evaluation System of Smart City" (Li \& Deng, 2011), "Comparison of China and other countries' evaluation index system for smart city" (Wang, 2013). 
urban economy can be converted into smart data to characterize the relevant indicators and profile the facet. Thirdly, the crossfaceted indicators should be further integrated, correlated and analysed. By visualizing the results of the analysis, a comprehensive city profile can be generated, which is able to serve specific information needs. And if all factors of each urban facet are integrated, a global profile of the whole city will be produced, that is, a profile of the digital urban space.

The city profile generated in the above steps can characterize "personality traits" and performance of the city from different perspectives. The former is a relatively static city profile with a certain update cycle, which is able to be used for urban evaluation, urban identity depicting, urban basic performance presenting, etc. The latter is the dynamic profile, reflecting urban environment information, regional density, public opinion, etc., which is used to show the real-time status of the city.

In the face of actual demands about smart city management and service, city profiles will be generated quickly by extracting and reorganizing the relevant content in the digital urban space and presenting the results in a visual form, which can provide new information services for the demands in the physical, social and cyber spaces. Meanwhile, data of different urban facets, related to the same problem, can be superimposed on one motion profile. And it will achieve a comprehensive display of the status quo of urban issues.

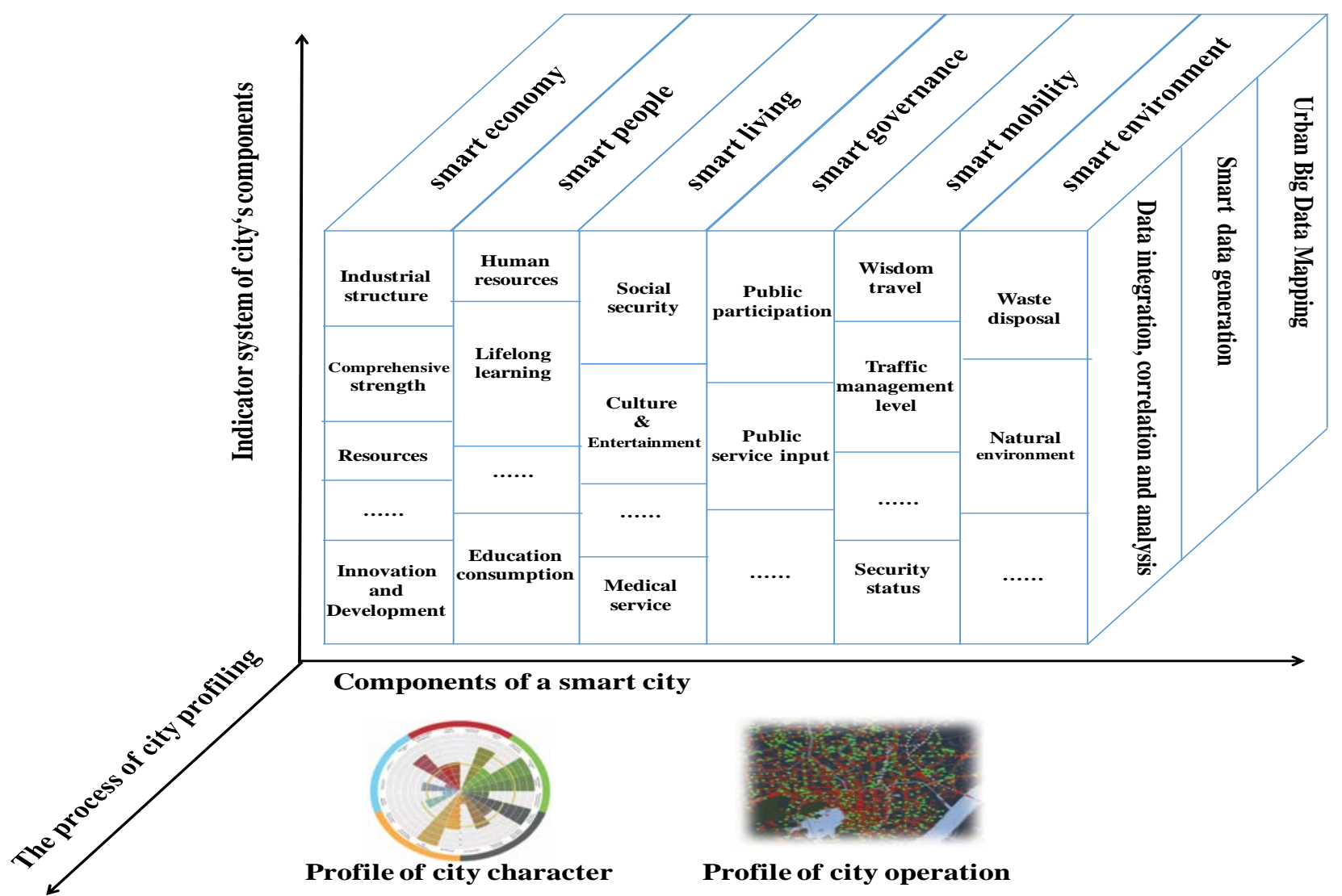

Figure 3. Urban facets profiling with smart data

\section{APPLICATION SCENARIOS OF CITY PROFILE}

City profile aims at providing information support to meet the needs of management, operation and decision-making for different users. It enables users to fully understand the operational status of different urban facets, which can help them solve problems. In order to provide a specific understanding about the application of city profile, following will illustrate three scenarios where city profile is used to assist urban emergency management, outline regional economic development, and break residents' information dilemma.

\subsection{Assistance to city emergency management}

As complex organisms, cities are always challenged by the capabilities of city emergency management due to the frequent occurrence of social security incidents and natural disasters. Intelligent emergency management systems have become an integral part of smart cities. From a practical point of view, the emergency management systems constructed in most cities have poor connectivity, and are weak in the capabilities of data perceiving, processing and emergency responding, which leads to the emergence of information islands ( $\mathrm{Li} \& \mathrm{Li}, 2016$ ). Therefore, it is necessary to enhance the capabilities of data acquiring, organizing, integrating, analysing and sharing to support emergency response in smart cities.

The conception of city profile proposed in this paper is able to well assist the emergency management decision-making by quickly, accurately and comprehensively obtaining relevant information. City profiling constructs a digital urban space to initially integrate basic data of the city by modelling and profiling the urban facets. In this case, when an emergency occurs, the digital urban space will be able to provide basic information related to the incident promptly for relevant departments. At the same time, it can also continuously collect, 
organize and analyse the required data, serving as a supplement to the basic information. In addition, using data of urban physical, social, and cyber spaces to profile different urban facets, city profiling provides emergency managers with comprehensive information on events that allows them to capture event dynamics from different perspectives. And it can also ensure the accuracy, objectivity and ease of use of the information when the city profiles are drawn with smart data.

Taking large-scale festival activities as an example, they usually have the features of large number of participants, long duration, and high degree of personnel aggregation, which are likely to trigger terrorist attacks, personnel stampede, and other emergencies. City profiles are able to provide effective support for precaution, handling and after-the-fact analysis. Prior to the activity, city profiles can provide relevant contingency plans for possible events by using the data of infrastructure, road distribution, population, etc. During the celebration, the distribution of traffic flow and people flow in the area can be profiled to generate regional heatmaps according to the data of traffic, telecommunication, etc. At the same time, by monitoring and presenting real-time information on social media, city profiles are able to help dynamically discover hot topics and abnormal information of relevant activities, and show the trends of online public opinion. In addition, by synthesizing a variety of information, relation schemas of core members and other event-related information can be also generated. Apart from the above, there are still a lot of data that can be used for emergency management and prevention. And reports of event situation, public opinion orientation and group behaviour can be generated to assist city emergency management decisionmaking. After the incident, these city profiles can be used as reference materials to improve emergency response capabilities and optimize emergency plans (Figure 4).

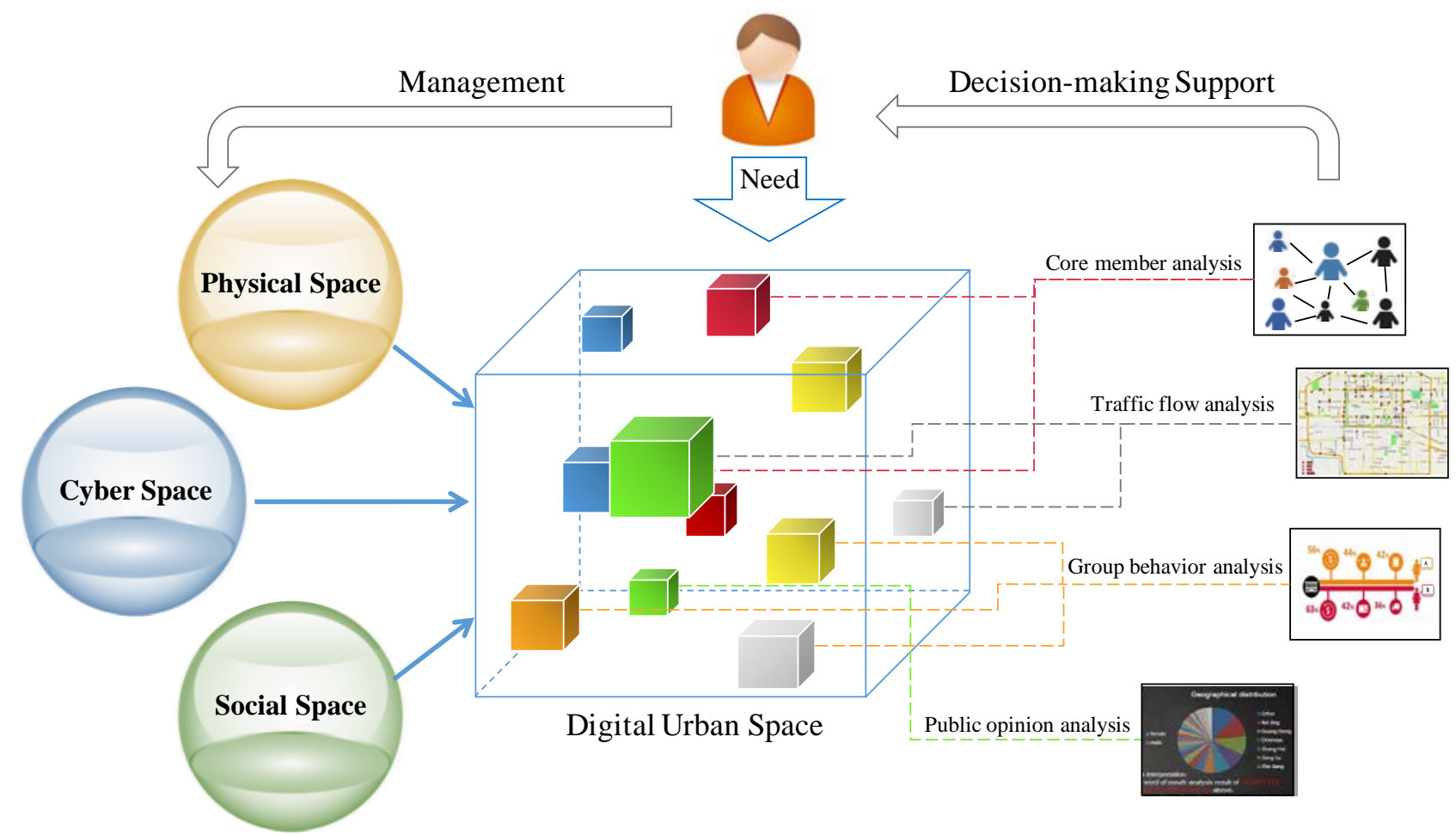

Figure 4. City profile assists city emergency management

\subsection{Outline of regional economic development}

The development of regional economy is influenced by many factors such as culture, education, technology, natural resources and environmental condition. City profiling constructs digital urban spaces so that the data related to the factors of regional economy in urban physical, social and cyber spaces can be effectively organized and analysed. Using these data, it is able to profile the economic development of urban area, and then provides data references for different users to understand regional economic development and solve their related issues.

Government agencies, for instance, can take advantage of city profiling to grasp the development trend of the local economy, and adjust their industrial structure according to the characteristics of the city so as to promote the rapid development of regional economy. And in the process of urban planning, the relevant departments can use city profiles as a basis for the division of urban functional areas, the construction of which will make it possible to make full use of the advantages of the existing local resources, technologies, environment, etc. It can enhance the industrial agglomeration ability and promote the regional economic integration. In addition, for the development of related industries, it is necessary to use urban data as an effective way to understand development level of industries. And city profiling is able to synthesize data in various fields associated with industrial development and present changes in relevant data from different perspectives. In this context, with the help of city profiles, the industry can fully understand its development advantages and disadvantages in the area, and formulate the development direction in line with the characteristics of local economic development.

In short, city profiling can comprehensively analyse and present development status of regional economy. It can provide different users with relevant data references, so that they can adjust their business direction and make strategic plans at the right time according to the description of regional economic development. 


\subsection{Breaking out of residents' information dilemma}

With the improvement of living standards, urban residents put forward higher requirements for the convenience of living. And an increasing number of people are accustomed to using network applications to solve a variety of problems, because the Internet is deeply immersed in their lives. For example, they use government websites to understand the policies, get various types of urban services through the e-government platform and query information about road condition, weather and other things with related applications. However, despite the large number of such information service applications, urban residents are still in a dilemma of information asymmetry where they have difficult access to the comprehensive and efficient information services that can provide them with a more convenient living and working environment.

City profile is able to shatter the ceiling of this dilemma. Through it, people are able to understand the status of the urban operation from different perspectives, which makes the relevant personnel have an overall control over the problems they want to solve. Apart from this, city profile can also be used to reduce information asymmetry in various public service industries such as traffic, healthcare, education and insurance by effectively organizing and analysing the urban data of relevant areas. It provides residents with informational decision support in a visual form. For example, Cennavi, a Chinese company that has established a joint laboratory with us, generates real-time city traffic profiles by integrating massive and multi-source urban data related to traffic to provide diverse urban services for residents' trip , including parking lot dynamic inquiry, traffic restrictions reminder, driving path planning, intermodal routing service, etc. It enables residents to quickly and comprehensively understand the city's traffic conditions and the status of its related services.

With the aid of city profile, residents can judge the status quo in all areas of the city from a bird's-eye perspective, which will help them improve individual information dilemma and reduce information costs. At the same time, it can also be a "shortcut" for residents to learn about a city. With city profiles drawn from real urban data, residents can understand the city's history, current status as well as future direction.

\section{CONCLUSIONS AND FUTURE WORK}

Sustainable development of cities faces many challenges that can be alleviated through the construction of smart cities. With the growing importance of data in urban management and operation, it is a viable option to use data as a tool of smart city construction. How to use the data in urban physical, social and cyber spaces to assist the construction of smart cities has become a key issue urgently needed to be solved. In this context, the conception of city profile, using urban data to create digital urban spaces, was proposed.

After a detailed analysis of the current urban space composed of physical, social and cyber spaces, this paper presented the concept of digital urban space. It was indicated that a recycling operation mechanism where urban physical, social and cyber spaces positively support the operation of a digital urban space, and the digital urban space assists the management of three types of urban space in reverse could be created with the construction of digital urban spaces. Then, digital urban spaces would help to achieve the goal of smart city construction.
In order to construct such a digital urban space, this paper further proposed city profile. The conception of it can be understood from two perspectives. On the one hand, it is a method of constructing digital urban spaces through which urban data can be used to reconstruct and analyse the issues of urban management and operation in digital urban spaces. On the other hand, it is a product of digital urban spaces that is used to provide information services for the three types of real urban space, presenting data analysis results in a visual way. City profiling can be divided into two core steps, urban facets modelling and urban facets profiling with smart data. The former disassembles urban space into several facets that can cover all the urban areas and have a particular function of representing the characteristics of urban facets. And according to the internal business logic of each facet, it constructs urban facet index systems of each facet and finally creates the framework of the digital urban space. The latter maps urban big data to digital urban spaces and then transforms it into smart data to obtain meaningful information. Smart data is used to describe the urban facets in the framework of the digital urban space. Finally, by integrating, linking and analysing smart data of different urban facets, city profiles are generated. In order to more concretely illustrate the practical application of city profile, this paper listed three specific application scenarios where it was used to assist urban emergency management, outline regional economic development, and break residents' information dilemma.

In conclusion, city profile proposed here is able to model cities with urban data, so that the actual problems of urban management and operation can be quickly and intelligently analysed and presented through the organization of relevant data. In addition, using data as a bridge to urban space, digital urban spaces constructed by city profiling promotes the interaction and intercommunication of the three types of urban space, making the city become an organism that can be managed and operated by data, which is able to provide information support for different users.

As a last point, we will further explore universal ways of urban facets division and its index systems according to the idea of city profiling. And we will also study the appropriate methods of data organization and processing, so that the concept of digital city space can be achieved.

\section{ACKNOWLEDGEMENTS}

This research is supported by the National Natural Science Foundation of China (Project Number: 71790612).

\section{REFERENCES}

Aguilera, U., Peña, O., Belmonte, O., and López-De-Ipiña, D., 2016. Citizen-centric data services for smarter cities. Future Generation Computer Systems, 76, pp. 234-247.

Albino, V., Berardi, U., and Dangelico, R. M., 2015. Smart cities: definitions, dimensions, performance, and initiatives. Journal of Urban Technology, 22(1), pp. 3-21.

Ang, L. M., Seng, K. P., Zungeru, A., and Ijemaru, G., 2017. Big sensor data systems for smart cities. IEEE Internet of Things Journal, 4(5), pp. 1259-1271.

Bakıc1, T., Almirall, E., and Wareham, J., 2013. A smart city initiative: the case of barcelona. Journal of the Knowledge Economy,4(2), pp. 135-148. 
Boschert, S., Rosen, R., 2016. Digital Twin-The Simulation Aspect. Mechatronic Futures. Springer International Publishing, Switzerland, pp. 59-74.

Chen, M., Wang, Q. C., Zhang, X. H, et al., 2011. Smart cities ranking: an effective instrument for the positioning of the cities? Urban Studies, 18(5), pp. 84-89.

Giffinger, R., Gudrun, H., Gudrun, Haindlmaier., 2010. Smart cities ranking: an effective instrument for the positioning of the cities?. Architecture City \& Environment, 6(12), pp.7-26.

Hashem, I. A. T., Chang, V., Anuar, N. B., Adewole, K., Yaqoob, I., Gani, A., et al., 2016. The role of big data in smart city. International Journal of Information Management, 36(5), pp.748-758.

Khan, M., Babar, M., Ahmed, S. H., Shah, S. C., Han, K., 2017. Smart city designing and planning based on big data analytics. Sustainable Cities \& Society, 35, pp.271-279.

Kitchin, R., 2014. The real-time city? big data and smart urbanism. Geojournal, 79(1), pp.1-14.

Kousiouris, G., Akbar, A., Sancho, J., et al., 2017. An integrated information lifecycle management framework for exploiting social network data to identify dynamic large crowd concentration events in smart cities applications. Future Generation Computer Systems, 78(2), pp. 516-530.

Lai, H. D.,2013. Study on Evaluation Index System of Urban Economic Development. Review of Industrial Economics, (9), pp. 26-32.

Li, G., Cheng, X., 2012. Research status and scientific thinking of big data. Bulletin of Chinese Academy of Sciences, 27(6), pp. 647-657.

Li, G., Li, Y., 2016. Construction of Emergency Decisionmaking Intelligence System Against the Background of Smart City. Journal of Library Science in China, 42(3), pp. 39-54.

Li, Y., Wang, X. Y., Mao, Y. Q., et al., 2016. Study on Evaluation Indexes and Methods of Urban Wisdom Traffic Development. Business, (4), pp. 249-250.

Li, X. Y., Deng, X. Y.,2011. Research on the Evaluation System of Smart City. Telecommunications Network Technology, (10), pp.43-47.

Lohr, S., 2012. The age of big data. New York Times, 16(4), pp. $10-15$.

Nuaimi, E. A., Neyadi, H. A., Mohamed, N., et al., 2015. Applications of big data to smart cities. Journal of Internet Services \& Applications, 6(1), pp. 1-15.

Patrizia, L., Silvia, G., Hend, F., et al., 2012. Modelling the smart city performance. Innovation the European Journal of Social Science Research, 25(2), pp. 137-149.

Shan, X. H., Zhang, X. Y., Liu, X. Y., 2018. Research on User Portrait Based on Online Review: Taking Ctrip Hotel as an Example. Information studies: Theory \& Application, pp. 1-10. doi: 10.16353/j.cnki.1000-7490.2018.04.018.
Sheth, A., 2014. Transforming Big Data into Smart Data: Deriving value via harnessing Volume, Variety, and Velocity using semantic techniques and technologies. IEEE, International Conference on Data Engineering, pp. 2-2.

Soja, E. W., 2015. The socio-spatial dialectic. Annals of the Association of American Geographers, 70(2), pp. 207-225.

Wang, F. Y., 2010. The emergence of intelligent enterprises: from cps to cpss. IEEE Intelligent Systems, 25(4), pp. 85-88.

Wang, J., Chao, L., Zhang, X., and Shan, Z., 2014. Survey of data-centric smart city. Journal of Computer Research \& Development, 51(2), pp.239-259.

Wang, S. X., Zheng, L., 2013. Comparison of China and other countries' evaluation index system for smart city. E-BUSINESS JOURNAL, (1), pp.92-100.

Xu J., Chen X. W., 2013. Construction of smart city model based on information space theory. Science \& Technology Review, 31 (22), pp. 56-59.

Xu G. Y., Tao L. M., Zhang D. P., et al., 2006. The dual relationship between physical space and cyber space. Chinese Science Bulletin, 51(5), pp. 610-616.

Zhang, D., 2006. Dual relations in physical and cyber space. Chinese Science Bulletin, 51(1), pp. 121-128.

Zeng, M. L., 2017. Smart Data for Digital Humanities. Journal of Data and Information Science, (1), pp. 1-12. 